\title{
Sotillo Picornell: arte, ética y fotografía
}

\author{
Jimena Sánchez Zumbado \\ Escuela de Artes Plásticas \\ Universidad de Costa Rica
}

\section{Resumen}

José Concepción Sotillo Picornell (1886-1957) fue un fotógrafo y periodista venezolano radicado en Costa Rica entre 1910 y 1935. Este precursor de la fotografía técnica en el país, apasionado de la vieja escuela inglesa e intenso defensor de la naturalidad y la verdad transmitidas por medio de la imagen será el primero en el país en discutir sobre la relación entre arte, ética y fotografía. Desde el Estudio Sotillo, uno de los más reconocidos y emblemáticos estudios fotográficos josefinos de la época, registrará con su lente a costarricenses de todas las clases sociales de inicios del siglo XX.

Palabras claves: Sotillo Picornell, fotografía, composición, historia, arte costarricense

\begin{abstract}
José Sotillo Picornell (1886-1957) was a Venezuelan journalist and photographer based in Costa Rica between 1910 and 1935. Precursor of technical photography in Costa Rica, passionate of the old English school and intense defender of the naturalness and the truth transmitted through the image, he will be the first person in the country to discuss the relationship between art, ethics and photography. From the Sotillo Studio, one of the most recognized and iconic photographic studios of San José at the time, he records with his lens all social classes of Costa Ricans from the beginning of the $\mathrm{XX}^{\text {th }}$ century.
\end{abstract}

Key words: Sotillo Picornell, photography, composition, history, Costa Rican art 
$\mathrm{P}$ ara inicios del siglo XX, la pequeña ciudad de San José tenía poco más de 50 años de conocer la fotografía: desde los primeros daguerrotipos y su laboratorio, el calotipo, el colidión hasta llegar al negativo y su positivado en papel. El liberalismo y el modernismo estaban en boga; las revistas culturales y científicas de la época reproducían en sus páginas imágenes de los paisajes costarricenses, así como de su gente, especialmente de la burguesía, aunque las clases más bajas también se interesaban -con menos frecuenciaen guardar para la prosperidad las imágenes de sus familias. Para una capital pequeña como San José, existían varios estudios fotográficos que ofrecían distintos precios y productos al mercado.

Es en esta época, aproximadamente en el año $1910^{1}$, cuando el fotógrafo venezolano José Concepción Sotillo Picornell llega al país. Autoexiliado por su lucha ejercida mediante la pluma contra la dictadura en Venezuela de Juan Vicente Gómez Chacón (Melgar, 2009, p.98), se afincará en la ciudad de San José. Las fuentes sacramentales nos dicen que Sotillo Picornell nace en el año 1886 en Pampatar, ciudad del Municipio de Sucre, Venezuela; hijo de Antonio José Sotillo Aguirre y Aguasanta Picornell Sánchez de Torres, ${ }^{2}$ y que el 29 de marzo de 1914 -aproximadamente cuatro años después de su llegada al país- casará en la iglesia del Carmen con la joven josefina Adelia Jiménez Salvatierra, nacida en San José el 17 de enero de 1887 e hija de Francisco Jiménez Sáenz y Apolonia Salvatierra. Los Sotillo Jiménez se asentarán en Barrio Aranjuez, en San José, siendo los padres de Arturo
José, Marta, Hortensia, Álvaro, Norma, Rodrigo y Hilda.

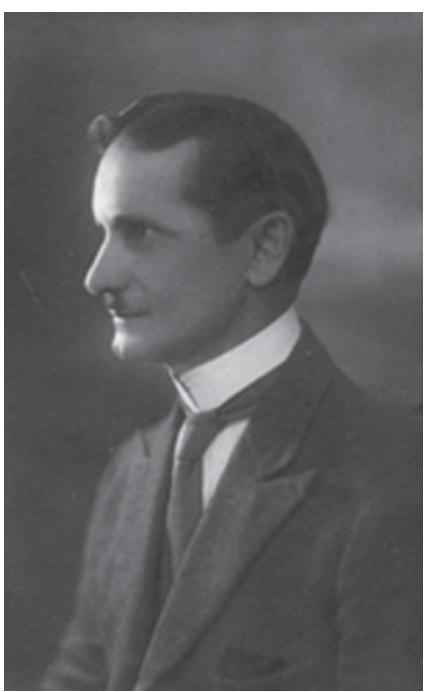

Fotógrafo desconocido: José Concepción Sotillo Picornell

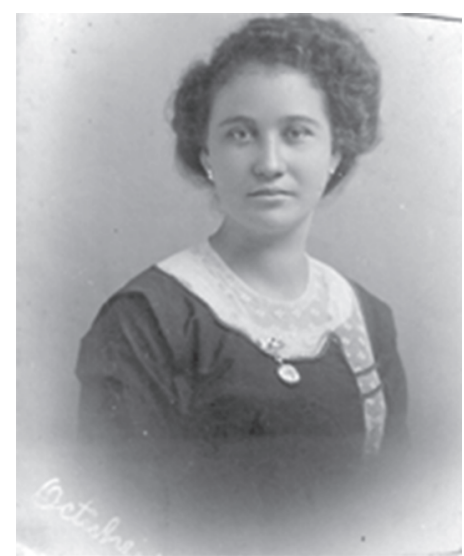

Fotografía realizada el 12 de octubre de 1911 por José C. Sotillo a su todavía novia, Adelia Jiménez Salvatierra

Propiedad de la familia Sotillo

Durante su vida en la nación costarricense, Sotillo Picornell se dedica intensamente a dos actividades que lo apasionan: la fotografía y las luchas político-sociales -estas últimas relacionadas principalmente con los problemas que agobiaban a su país natal-, 
materializándolas ambas por medio de su otra profesión: la de periodista. El presente artículo se concentrará únicamente en el análisis de la obra y pensamiento de José Concepción Sotillo en su faceta de fotógrafo.

\section{Inicios del Estudio Sotillo: un ta- ller técnico de fotografía en Costa Rica}

A pesar de que José Sotillo ejerció en Costa Rica únicamente de 15 a 20 años su profesión de fotógrafo, su legado es sumamente interesante de estudiar, especialmente por la sensibilidad y dominio técnico que plasma en sus fotografías.

La imagen más antigua captada por el lente de José Concepción que fue posible localizar se publicó en Caracas, Venezuela, en el año $1910^{3}$ por una de las primeras y la más importante revista de variedades de ese país: El Cojo Ilustrado, producida y editada por José María Herrera Irigoyen en la imprenta El Cojo, que "utilizaba para reproducir las imágenes el primer taller de fotograbado mecánico que se importó desde Europa a Venezuela" (Di Mare, 2009, p.13).

Esta fotografía se titula "Niñas guajiras vendedoras de leche" y formó parte del número 199 de dicha revista quincenal, que llegó a tener más de 3.000 suscriptores entre los años de 1892 y 1915 que correspondieron a su publicación. El Cojo Ilustrado es considerada aun en la actualidad como la mejor publicación de su tipo que ha existido en Venezuela, bastión del Modernismo y del desarrollo literario de ese país. ${ }^{4}$

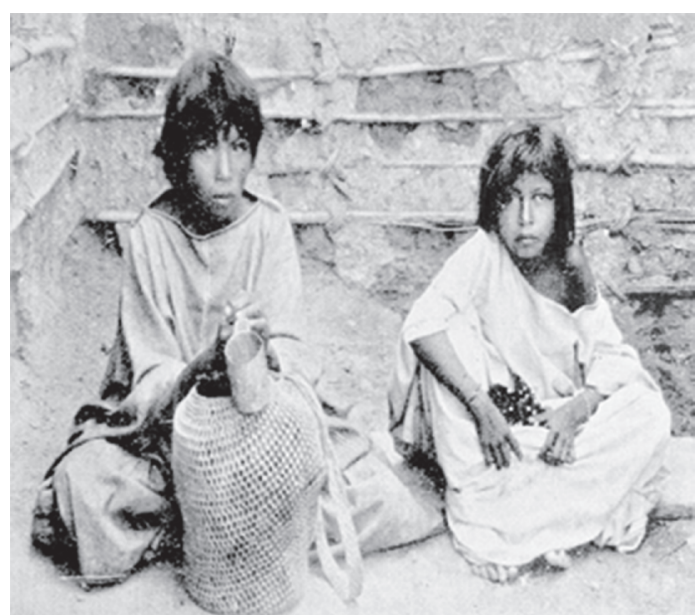

Sotillo Picornell:

"Niñas guajiras vendedoras de leche"

Revista El Cojo Ilustrado, N. ${ }^{\circ}$ 0199, 1910, Venezuela

Desde esta temprana imagen -tendría al publicarla aproximadamente 24 años de edad-se puede descubrir su interés por la realidad, las formas naturales y transparentes, valores importantes tanto en su práctica fotográfica como en la periodística.

El siguiente dato que se tiene de José Concepción es, como se dijo anteriormente, su llegada a Costa Rica y lo ubica, según tradición oral de su familia, trabajando para el estudio fotográfico de los hermanos Paynter, cuyo moderno estudio se encontraba a un costado del Parque Central de San José. No se sabe ni con exactitud por cuánto tiempo laboró ahí ni cuáles fueron sus funciones en dicho estudio, pero prontamente se inició en la fotografía comercial de forma independiente. Se podría deducir que aproximadamente un año después de su llegada Sotillo sería dueño de su propio estudio fotográfico, esto con base en el dato que aportan dos fotografías de su todavía 
novia Adelia Jiménez S., fechadas el 12 de octubre de 1911 y de su autoría.

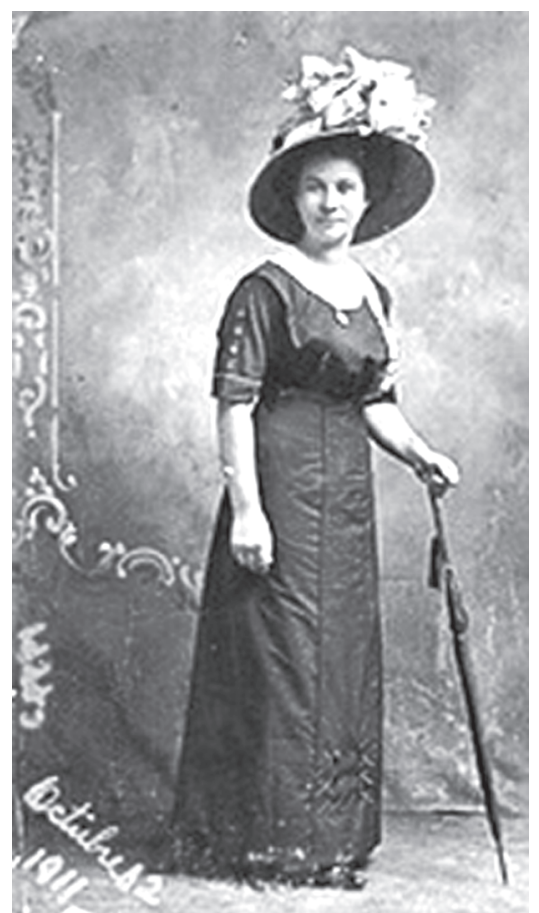

Fotografía realizada el 12 de octubre de 1911 por José C. Sotillo

a su todavía novia, Adelia Jiménez Salvatierra Propiedad de la familia Sotillo

Sotillo se especializaría principalmente en el campo del retrato-aunque también realizará trabajos fotográficos a distintas compañías siendo precursor en el país de este tipo de contratacióny será por este medio que le dará el sustento a su familia. En su renombrado estudio fotográfico Sotillo's Studio, ubicado en el centro de San José a "veinticinco varas al oeste del parque Morazán sobre la calle de los Damas", registrará con su lente a costarricenses de todas las clases sociales de inicios del siglo XX. Al parecer su estudio tuvo también otra localización anterior a la citada, pero no ha sido posible encontrar referencias sobre este dato.

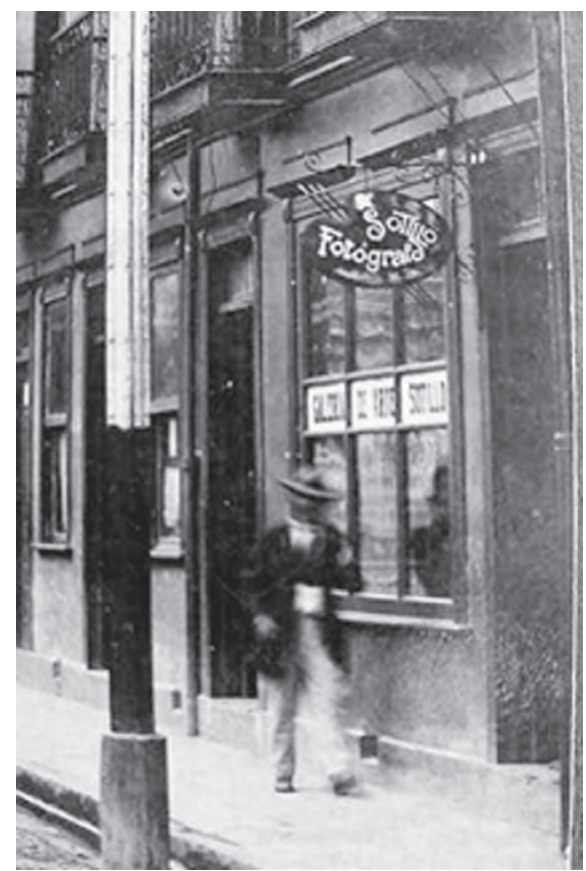

Fotografía del Estudio Sotillo, sobre paseo de los Damas

Propiedad de Ana Isabel Herrera Sotillo

Como él mismo relata: "con motivo del establecimiento de mi Taller Fotográfico anuncié al público de Costa Rica que mis trabajos se realizarían obedeciendo a un plan técnico [...] los proventos económicos [de su taller] han venido a comprobar que sí hay público banal para los procedimientos empíricos de supuesto embellecimiento artificial; existía una patente necesidad de un taller técnico de fotografía".

Sobre la formación profesional de Sotillo se conoce poco, pero se puede suponer que tuvo estudios en el campo de la fotografía (formales o autodidactas), probablemente en Inglaterra -se sabe que en su juventud viajó por Europa y Estados Unidos de América-, pues en textos de su autoría se muestra como conocedor de las posturas técnicas y conceptuales de las dos escuelas de fotografía más importantes de la época: 
la inglesa -la escuela tradicional-y $l a$ norteamericana -la nueva escuela-; condenaba desde su posición técnica el "sistema empírico que ha sido hace veinte años el sistema de trabajo en el país" (Sotillo,1930, p.2). Además fue miembro de la Real Sociedad Fotográfica de la Gran Bretaña, fundada en 1853 por Roger Fenton, que se mantiene activa hasta la actualidad. Él mismo menciona su afiliación a la escuela profesional-escuela convencional inglesade Dover Street, zona de importancia histórica en la evolución del diseño y de la fotografía en Inglaterra.

La fotografía en Inglaterra había tenido un desarrollo veloz y al mismo tiempo lleno de conflictos entre sus diferentes seguidores: hasta finales del siglo XIX todavía se debatía constantemente sobre si la fotografía podía ser considerada como arte en sí misma, si únicamente servía para reproducir una imagen, o si su mayor aporte era solamente apoyar al pintor en el proceso de creación de la imagen que se deseaba interpretar.

Sotillo Picornell se declara seguidor de la escuela inglesa, al punto de defender su trabajo de forma estricta y moralista: para él, el mantenimiento de su posición técnica y conceptual al momento de desarrollar su obra, tanto comercial como artística, es un asunto de ética y de compromiso con su propio pensamiento. Él mismo proclama que ni los gustos de su público ni los beneficios económicos han sido capaces de desviarlo del "programa que establecimos al iniciar nuestra empresa" (Sotillo, 1930, p.11).

"Su programa", como lo declara en dos interesantísimas publicaciones que hace en el diario costarricense $L a$ Nueva Prensa-con fecha del 10 y 11 de junio de 1930- se refiere a la relación de los valores éticos y técnicos de la antigua escuela que, como fotógrafo, se había planteado al establecer su estudio fotográfico.

En el texto cita como sugirió a un amigo fotógrafo que "adopte la escuela convencional [la escuela inglesa...] que bastaba con ampliar sus claraboyas, no desajustar sus objetivos y adoptar un plan de retoque franco, severo, honrado". (Sotillo, 1930, Año IX, N. ${ }^{\circ}$ 2550, p.6)

Esta escuela inglesa era intensa en sus posiciones y en la representación realista, a veces casi descarnada de la situación, reflejada tanto en sus paisajes como en sus modelos. No buscaba la belleza por ella misma, sino más bien la descripción -física o sicológica- del personaje por medio de sus virtudes o defectos naturales (sus líneas de expresión, canas, tersura, etc.), a diferencia de la escuela americana, que prefería transformar -casi siempre- en belleza lo que se capturaba por medio del lente. Incluso se sabe ahora que las crudas imágenes de la Guerra Civil en Estados Unidos fueron manipuladas por los fotógrafos -tanto en el lugar mismo de la acción, moviendo los cuerpos para mejorar la composición, como retocando las imágenes reproducidas en los laboratorios fotográficos ambulantes- para hacerlas ver más heroicas e impresionantes, y ipor qué no?... ihasta bellas!

\section{Composición y técnica: "adoptar un plan de retoque franco, severo, honrado"}

En cuanto al recurso de la composición en la fotografía, Sotillo demuestra conocimiento y oficio; recurre repetidas veces al equilibrio asimétrico y a la aplicación de la ley de tercios, 
proponiendo composiciones simples y poco trucadas que le dan al modelo humano una gran naturalidad, tanto en la pose como en la expresión del rostro.

En los retratos centra el enfoque en el rostro permitiendo así un levísimo desenfoque en la periferia de la imagen, logrando con esto suavizarla. La utilería que emplea es simple, los telones de fondo no roban protagonismo y pocas veces recrean espacios imaginarios, costumbre común en la época. En cuanto al trabajo de laboratorio, Sotillo solía virar las imágenes, es decir, las reproducía en tonos sepias con lo que lograba contraste y al mismo tiempo una gama de valores tonales más cálidos que los logrados con el blanco y negro.

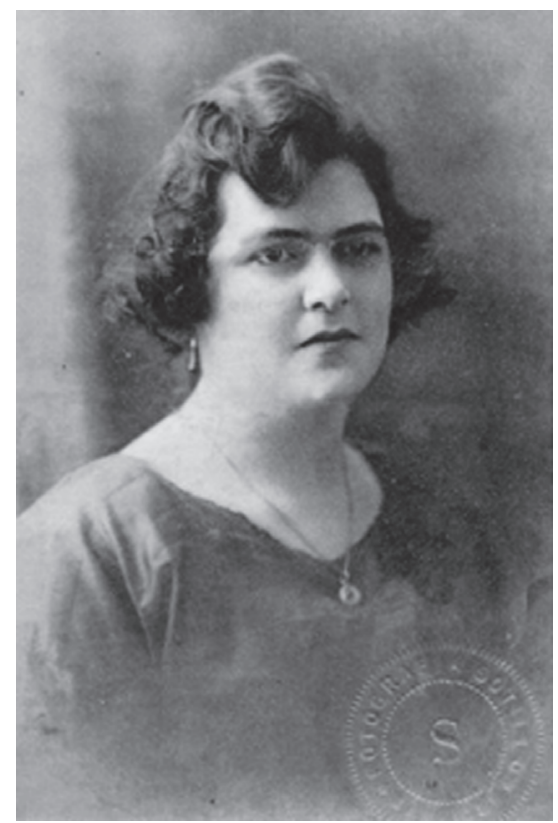

Rafaela Soto Pereira, vecina de Sabanilla de Alajuela

Aprox. 1923. Colección personal de la investigadora

Aunque probablemente muchas de sus fotografías necesitaron de algún grado de retoque o corrección, debido a las dificultades técnicas de la época (José Concepción conoció a su esposa Adelia al contratarla precisamente para que iluminara -es decir, coloreara- o retocara a mano las fotografías en blanco y negro de la época), Sotillo se declara enemigo acérrimo de la manipulación de la imagen: "Esas señoras ancianas cuyos rostros no revelan una sola línea de su paso por la vida, y esas señoritas que no tienen una sola modulación en su tipo de belleza, en mayor o menor grado, en sus retratos, o tienen un concepto equivocado de su propia belleza". (Sotillo, 1930, p.2)

Por ejemplo, en la fotografía de Angelina Solano García (aprox. 1913) es posible dar fe de la estrecha relación entre la palabra y la obra de José Concepción: una imagen simple, compuesta en tercios (incluso la línea del tercer tercio corta justo a la mitad la figura), utilizando utilería tan sencilla como la joven misma que retrata: una campesina de poco más de 20 años, segunda esposa de Francisco Chinchilla Ulloa y vecina de Aserrí. El mantillo que cuelga de su brazo podría indicarnos que la fotografía se tomó con motivo de su boda, pues es un accesorio común en este tipo de fotografías. La mirada del observador recorre la imagen desde la izquierda, donde el fondo grácilmente se ha dejado incompleto, difuso; luego se dirige a las manos casi juntas -que se ubican además en el inicio de la zona áurea de la imagen-; mientras se observa la sencillez del vestuario (mantillo tejido, enagua larga de tela brusca, blusa clara con botones al frente, calzada), el ojo pasa ahora a la mesita y de ahí a las flores, para finalmente posarse en el rostro de la mujer quien mira directamente a la cámara, sin reservas ni poses, dejando ver la lozanía propia de su edad, y que de forma muy natural (y poco común en la época) esboza una pequeña sonrisa. 

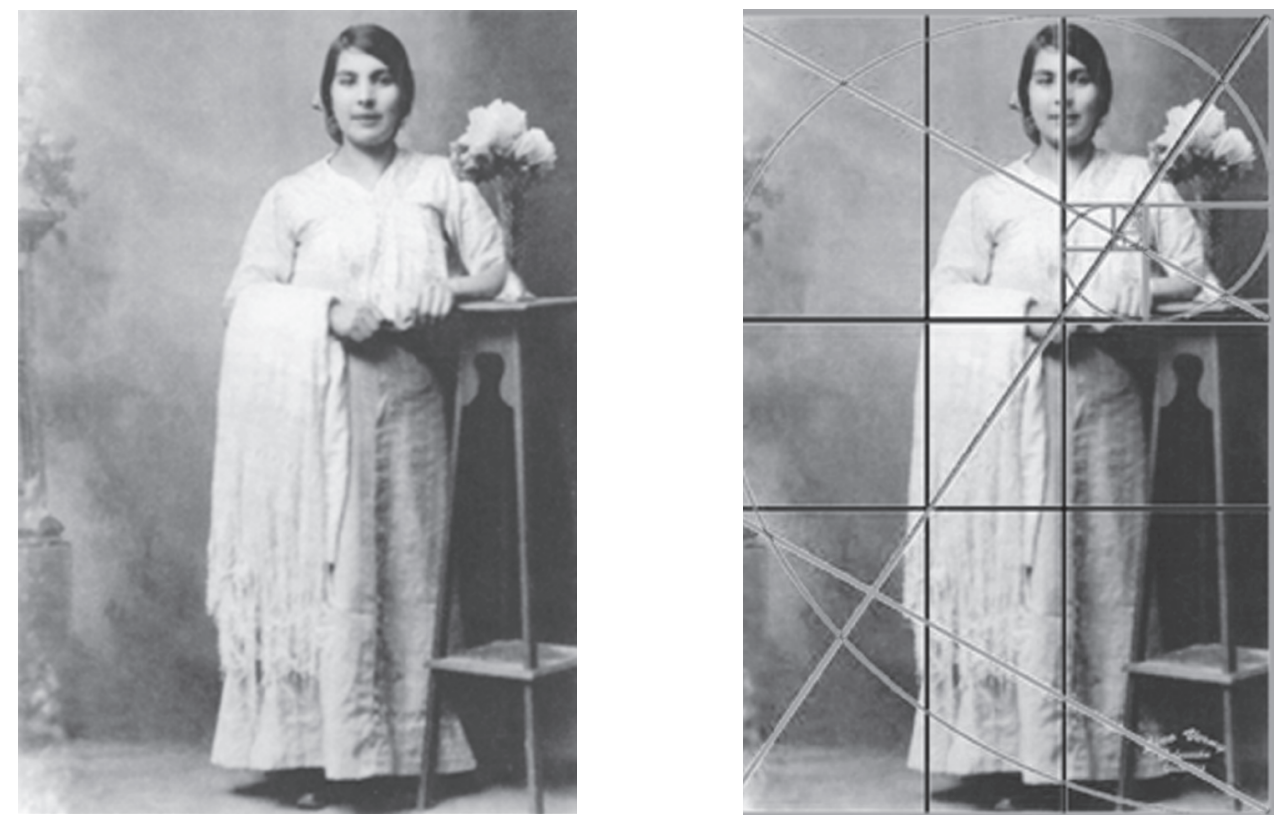

Sotillo Picornell: Angelina Solano García,

Aprox. 1913. Colección personal de la investigadora

Sotillo consideraba que falsear la realidad de la imagen mediante trucos de retoque era ofensivo, tanto para su propia ética profesional, como por el error que sería colaborar con la reproducción del mal gusto; es más, expresa un sentimiento de responsabilidad para "educar" al público hacia una perspectiva más real y natural del entorno y de su propia persona.

Muy probablemente por esta naturalidad tan buscada por Sotillo, es que crea una serie de bellas imágenes familiares. En esta hermosa fotografía reproducida a continuación y tomada en su casa de habitación, pero con un aire de estudio fotográfico, Sotillo recurre de nuevo a distribuir los elementos bajo la ley de tercios: crea con los pies de los modelos una diagonal de izquierda a derecha que da dinamismo a la composición, compensando así la línea recta formada por las tres cabezas de los niños (sus hijos Hortensia, Arturo y Marta) que son el foco de atención principal y que se encuentran precisamente sobre la línea del primer tercio horizontal. La viveza que proyectan los ojos de las niñas es suavizada por la ausencia de mirada del niño, quien, al centro, simula leer un libro mientras acerca suavemente su cabeza a la de su hermana menor, creando al mismo tiempo un descanso visual mediante el espacio vacío entre las cabezas de los dos niños de la izquierda y su hermana a la derecha -la cual se encuentra, además, justo en la zona áurea-. 

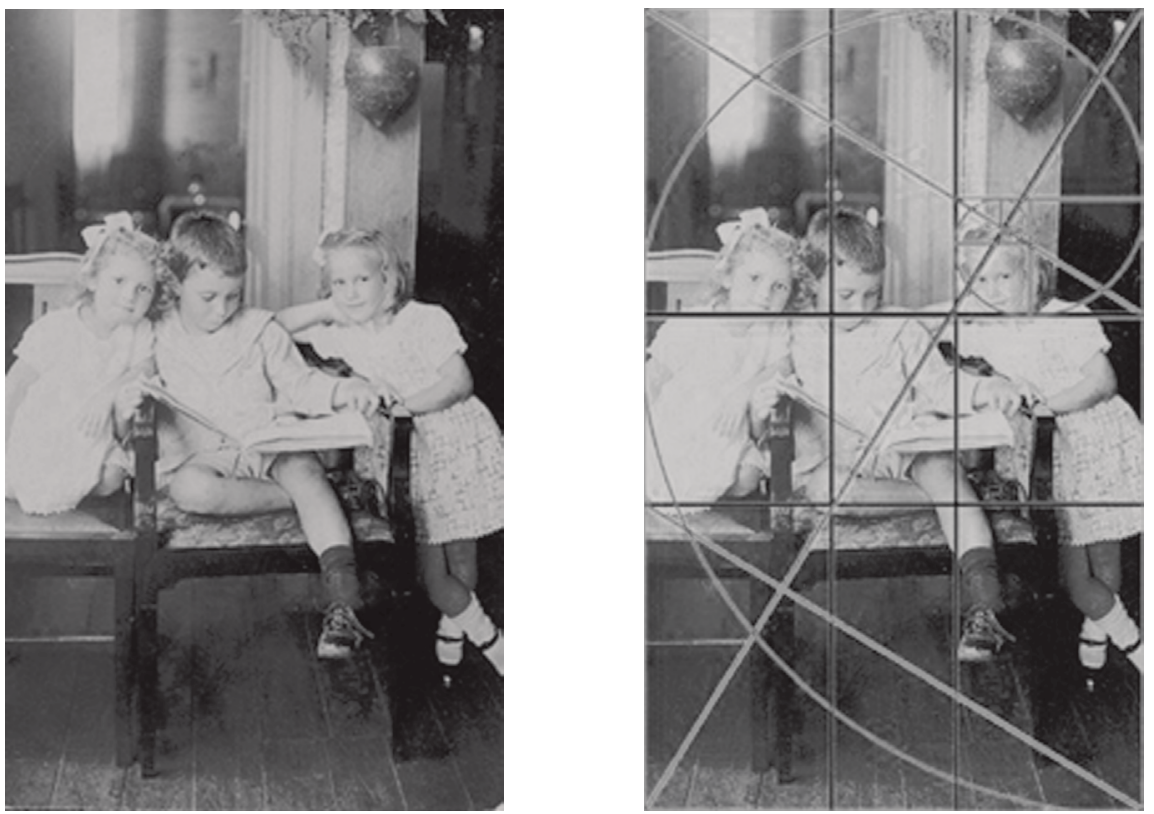

Sotillo Picornell: Hortensia, Arturo y Marta Sotillo Jiménez

Aprox. 1922. Colección de Ana Isabel Herrera Sotillo

La Exposición Nacional de Artes, Oficios e Industrias de 1917

La Exposición Nacional de Artes, Oficios e Industrias de 1917 fue concebida como elemento amortiguador de las molestias político-sociales que estaba generando el gobierno de Federico Tinoco Granados, quien se había hecho del poder por medio de un golpe de Estado y unas, todavía hoy, dudosas elecciones presidenciales.

Mediante esta muestra el Gobierno intentaba resaltar el imaginario social de Costa Rica como un país "agrícola, pacífico y educado” (Urbina, 2013, p.158).

Esta exposición se realizó en la Escuela Metálica. El jurado para la escogencia de los premios en Bellas Artes en fotografía estuvo integrado por el fotograbador Próspero Calderón, Fernando Zamora y el profesor José Fidel Tristán, otorgándoseles Medalla de Oro a José Concepción Sotillo y al herediano Amando Céspedes Marín, Medalla de Plata a Avelino Alsina, a los hermanos Hernández y a Manuel Gómez Miralles, y finalmente Mención Honorífica a Paynter y Robert.

Sotillo participaría con cinco obras, dos ejercicios de retrato femenino a contraluz y tres paisajes. Todas las obras de Sotillo fueron publicadas en el catálogo de la exposición. Una de las obras "paisaje josefino, vista parcial de la Sabana" y titulada Crepúsculo fue publicada el 1. ${ }^{\circ}$ de noviembre de 1917 en Athenea, una de las revistas modernistas más importantes y activas de la época, dedicándosele un espacio llamado "Ecos de la exposición": "en el que se advierte la mano firme del artista, su pulcra expedición y un gran conocimiento en el difícil arte del claro-obscuro" (Revista Athenea, 1917, n. ${ }^{\circ} 3-4$, p.111).

En la obra Retrato contra luz la modelo de Sotillo -quien parece ser su esposa Adelia- se encuentra totalmente 
de perfil y en un plano abierto, mientras mira una reproducción en bulto de una escultura clásica. Sus manos con guantes tocan la base de la escultura, mientras que el resto de la indumentaria de la mujer se compone de un vestido de manga larga, abrigo y sombrero. La luz que ilumina el espacio desde atrás se transforma en el fondo y recorta con precisión los contornos de ambas figuras. Sotillo vuelve a recurrir en esta obra a su clásica

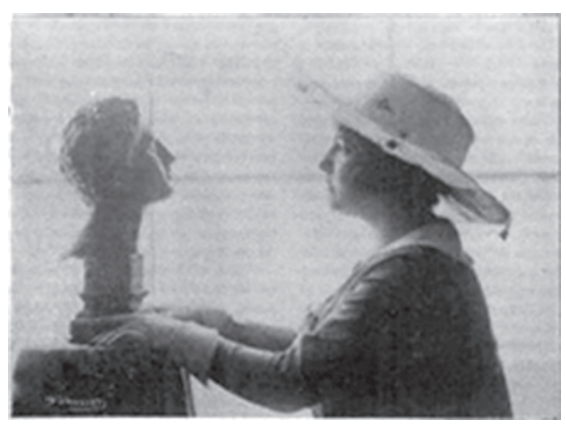

Sotillo Picornell: Retrato contra luz Exposición Nacional, 1917, en Revista Athenea

En las otras dos imágenes que se presentan a continuación Sotillo vuelve a jugar con la luz, esta vez natural, al permitir que la caída del sol recorte las formas y las vuelva masas oscuras; la composición de Crepúsculo se vuelve más plana, el tercio inferior marca la línea del horizonte y la profundidad solo se reconoce por la escala de tres árboles que se hacen más pequeños mientras la mirada se aleja.

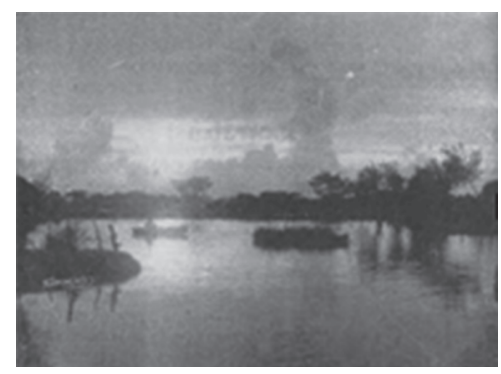

Sotillo Picornell: Paisaje Josefino

Exposición Nacional, 1917, en Revista Athenea composición mediante la ley de tercios, consiguiendo con esto dividir compositivamente la imagen en tres piezas de igual medida, con el objetivo de lograr equilibrio -al ser los cortes del mismo tamaño- pero a la vez da dinamismo e interés -pues los bloques se encuentran en número impar-. El recorrido visual se desplaza constantemente en forma de $U$ entre las dos figuras, pues se perciben como una sola unidad.
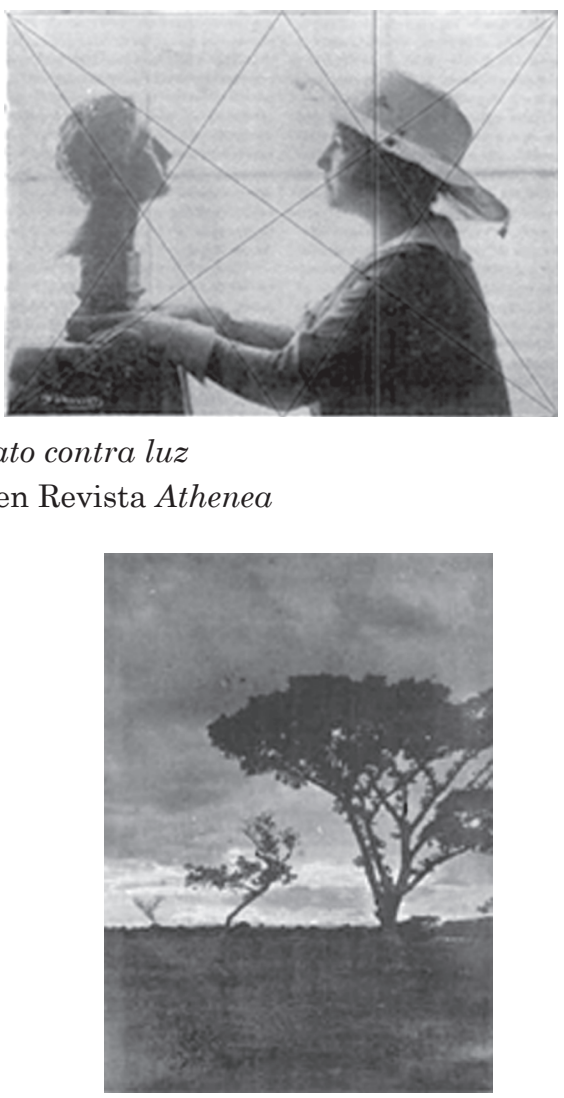

Sotillo Picornell: Crepúsculo

Exposición Nacional, 1917, en Revista Athenea

En cuanto a la exposición en general, la fotógrafa Sussy Vargas apunta que "la importancia real de la Exposición Nacional de 1917 fue que mostró a todo un grupo de artistas y artesanos que generaría las bases de los movimientos 
artísticos posteriores, consolidaría estilos y fortalecerían las instituciones" (Alvarado, Hernández y Vargas, 2004, p.52).

\section{Las cámaras de Sotillo}

Del equipo fotográfico con el que Sotillo realizaba sus imágenes, hay únicamente dos referencias y casualmente ambas datan de 1919. La primera se encuentra en un anuncio publicado en un diario nacional del que no se cita el nombre, en donde Fotografía Sotillo se promociona como agente para Centro y Sudamérica de los objetivos anastigmáticos Euryplan, producidos por la Schulze y Billerbeck, en Goerlitz, Alemania.

Este tipo de objetivo ${ }^{6}$ que se aprecia en el fotograbado que ilustra el anuncio, y probablemente tomado de los catálogos que la empresa distribuía para realizar los encargos, permitió la creación de las cámaras "de bolsillo", es decir, el equipo portátil con el que se superaron las enormes e incómodas cámaras profesionales de la época, iniciando así la popularización y democratización de la fotografía. Sería lógico suponer que Sotillo utilizara, dentro de su equipo, las cámaras que publicitaba y distribuía. Varios detalles más nos brinda este anuncio: el estudio se llama en 1919 Fotografía SOTILLO (y no J.C. Sotillos's Studio como se nombra en fotografías posteriores), posee número telefónico -437- y apartado postal -928-, y dice pertenecer a J.C. Sotillo y Cía., aunque no se tiene noticia de que José Concepción tuviese algún tipo de socio.

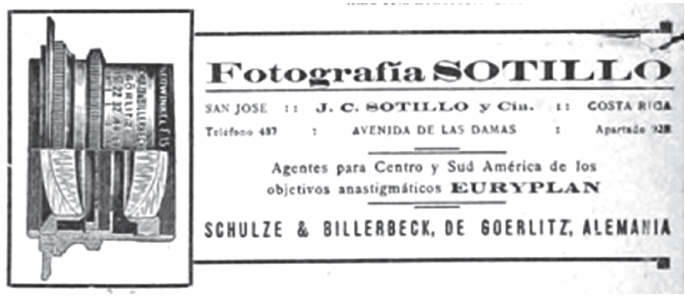

Fotografía SOTILLO

Anuncio impreso, 1919

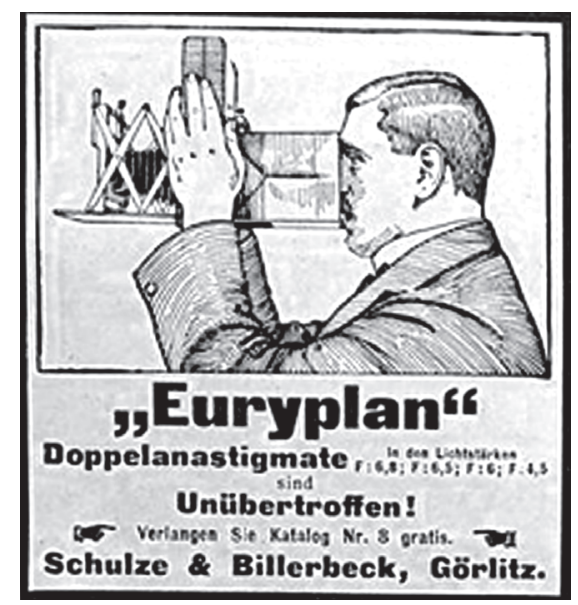

Anuncio Objetivo Euryplan, $1910^{7}$

La segunda reseña sobre el equipo que utilizaba Sotillo es la citada en el relato de José Marín Cañas (Costa Rica, 1904-1980) sobre la quema del periódico La Información, acaecida en 1919 y que propiciaría la caída del dictador Tinoco Granados. Este delicioso relato de un Marín Cañas de 14 años y narrado en primera persona brinda un perfil no solo del momento histórico, sino también de la personalidad del fotógrafo Sotillo. Por la riqueza de detalles, se transcribe a continuación:

[...] en aquel momento cuando toda la humanidad cogía el camino de la casa, apareció por la acera, llena de congojas y de máquinas, un caballero venezolano, radicado desde hacía muchos años en el país, entroncado con 
familia costarricense, respetado exiliado de Venezuela, su país, sobre el que jineteaba el centauro monstruoso de Juan Vicente: el fotógrafo don José Sotillo Picornell. Estaba instalado con su negocio de fotografía a la vuelta, sobre la misma Alameda de las Damas, a 25 varas de la esquina misma del parque, para que las señas sean castizas.

Ver el cronista al fotógrafo y comprender que los dioses le habían brindado la ocasión de inmortalizarse, fue uno. Era necesario salir en aquel hecho histórico a como diera lugar, a pesar del calor del incendio, de lo tardado de la fotografía y de los tiros, que podían arreciar y hasta convergir sobre uno.

Llegó el Sr. Sotillo, abrió las descomunales tres patas de un cajón del más adelantado sistema fotográfico de la época. Le echó un vistazo al sol, comprendió que la luz lo ayudaba, sacó un inmenso trapo negro y se escondió tras la máquina, como quien abre un paraguas para librarse de la tormenta. En aquel preciso momento, sonaron otros tiros, pero ya no eran del "Bella Vista", sino del quiosco, sitio en el que la policía se había fortificado, disponiéndose a amedrentar a tiros a los asaltantes con descargas a lo largo de la calle.

El cronista pensó prescindir del retrato por la cercanía de las estampidas del Mauser, pero sacando fuerzas de flaqueza, soportó el lento pasar de los segundos mientras el fotógrafo enfocaba. Se salió dos veces, como si los tiros no sonaran, fuera del trapo negro y le dio dos o tres toques mágicos al lente. Todo lo hacía con una calma, con un señorío que en él era costumbre inveterada. Creo que en la historia de la humanidad no han transcurrido segundos más largos... La policía seguía disparando, pero el fotógrafo no disparaba... En medio de la batahola, oí el disparo del obturador. No sé, no sé cómo en la bulla del incendio, el crepitar de las llamas, los disparos de la policía pude reconocer, con sensual complacencia, como una caricia callada, aquel "tic" que me liberaba de la gran angustia

No es necesario que lo diga. Desaparecí de la escena como un borrón. Creo que ni el mismo fotógrafo se dio cuenta de que pasé a su lado [... $]^{9}$

En este texto Marín Cañas nos comenta que José Concepción "abrió las descomunales tres patas de un cajón del más adelantado sistema fotográfico de la época. Le echó un vistazo al sol, comprendió que la luz lo ayudaba, sacó un inmenso trapo negro y se escondió tras la máquina"; es decir, Sotillo salió probablemente con una de las cámaras de trípode de su estudio, y no con una de las portátiles que distribuía. Fantaseando un poco, casi es posible imaginárselo oyendo el estruendo a la vuelta de su negocio, asomándose a la puerta e, impulsado por su olfato de periodista, devolverse al interior, echar un rápido vistazo sobre el estudio y tomar la cámara que tenía preparada, lista en espera de la clientela, salir de nuevo... e inmortalizar el momento.

Para completar la detallada crónica de Marín Cañas se presenta a continuación lo infaltable: la imagen fotográfica lograda en la revuelta. En primer plano a la izquierda, José Marín; al fondo a la derecha, es posible distinguir el humo que salía de las oficinas del periódico oficialista. A la izquierda, fuera de foco y a escasos 50 metros, el 
Parque Morazán. En la esquina inferior derecha, el sello blanco con el nombre del autor. Según comentario de Ana Isabel Herrera Sotillo, nieta de José Concepción, luego de positivar la imagen lograda, la mantuvo durante algún tiempo en el ventanal de exhibición de su negocio, como era costumbre hacer en los estudios fotográficos con sus fotografías más bellas o interesantes. Enviados del general Tinoco llegaron al lugar para intimidarlo y obligarlo a quitar la fotografía de la vista pública, lo que Sotillo no hizo; poco después, alguien no identificado quebró el vidrio del exhibidor y la robó.

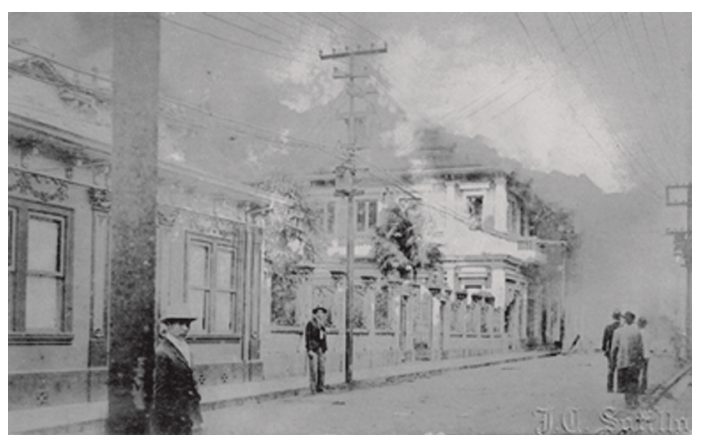

Sotillo Picornell: Quema de La Información San José, 1919. Colección de la familia Sotillo

\section{El adiós de Sotillo Picornell}

Aunque la despedida pública de Sotillo Picornell como fotógrafo se da en el año 1930, por medio de dos sendos artículos en el diario La Nueva Prensa, se conoce que abandonó definitivamente Costa Rica cinco años después, volviendo a Venezuela luego de la caída de Gómez Chacón. En los artículos que se mencionaron anteriormente, además de otros temas, refiere que abandonará la fotografía de forma definitiva para dedicarse en su país natal a su profesión de periodista; deja su estudio (equipo, establecimiento y negativos) en manos de Luis Guillermo Arias, su protegido, discípulo y amigo, quien tiempo después renombrará el negocio como Fotografía Arias. Sotillo será acompañado a Venezuela por algunos de sus hijos, mientras que otros continuarán viviendo en Costa Rica y dejan descendencia en el país.

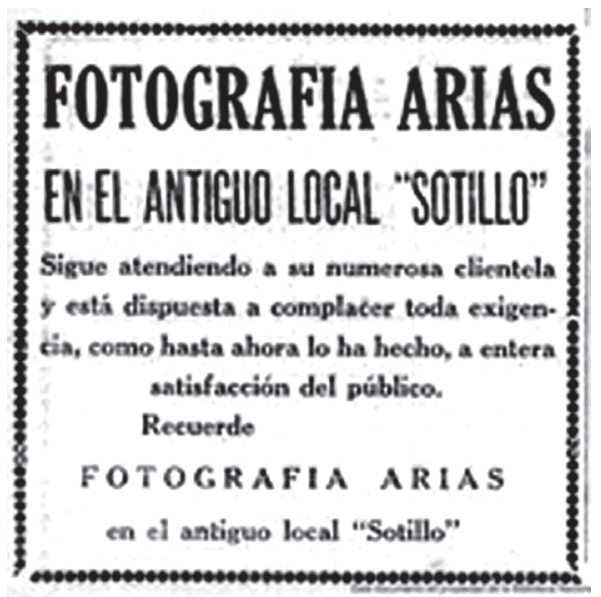

Anuncio de Fotografía Arias

Propiedad del Archivo de la Biblioteca Nacional de Costa Rica

En 1957, durante la dictadura en Venezuela, esta vez de Pérez Jiménez, José Concepción -ya de 71 años de edad- es encontrado malherido dentro de la cajuela de un automóvil; fallecería luego de una agonía de cinco días. Parece ser que su pluma siempre inquieta, que fue el distintivo de su personalidad, no perdió vigor con los años; esto daría razones políticas para que los partidarios de la dictadura acabaran con su vida. 


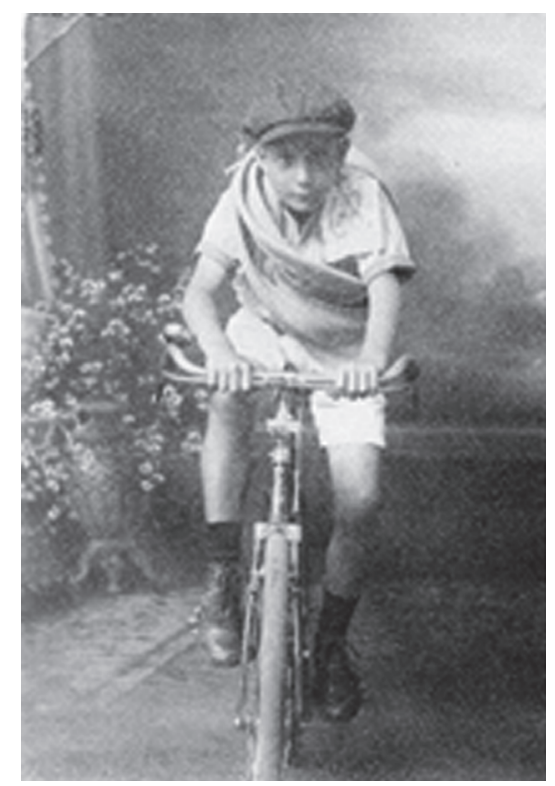

Sotillo Picornell: Arturo Sotillo Jiménez vestido de ciclista

Aprox. 1926. Propiedad de la familia Sotillo

Una vez publicados los textos en la prensa del año 1930, José Concepción, fiel a su palabra y retomando de nuevo su ideal de periodista -al que de una $u$ otra forma había seguido atado durante su vida en Costa Rica- no volvería a hacer fotografía ni comercial ni artística. Su legado probablemente más importante, después de la calidad de sus imágenes fotográficas, es su posición ordenada, metódica y su compromiso casi académico con los valores que profesaba sobre la naciente profesión de fotógrafo tanto en su faceta comercial como artística.

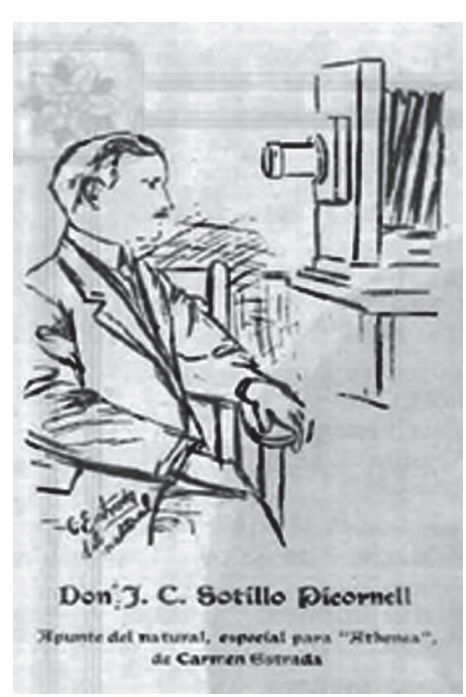

Carmen Estrada: Don J.C. Sotillo Picornell Publicada en Athenea

(1917 año 10, n. ${ }^{\circ}$ 3-4, pág.111)

\section{Notas}

1. Dato familiar proporcionado por Ana Isabel Herrera Sotillo, nieta de J. C. Sotillo.

2. Acta de Matrimonio entre José Sotillo Picornell y Adelia (Jiménez) Salvatierra, Parroquia de El Carmen de San José, Costa Rica, con fecha del 29 de marzo de 1914. Libro Matrimonios El Carmen, 1914.

3. Aunque no se puede asegurar que 1910 fuese la fecha de realización de la fotografía, pues además es el año aproximado en que Sotillo llega a Costa Rica, por lo que pudo haber sido realizada antes de esa fecha.

4. www.mariafsigillo.blogspot.com/2011/06/ el cojoilistrado.html Recuperado el 4-1-2015.

5. Anuncio en el diario costarricense $L a$ Hora, publicado en el año 1919, sin referencia de número ni día.

6. Inventado en 1889 y calculado matemáticamente por P. Rudolph. 
7. Imagen encontrada en eBay y es posible localizarla entre los antiguos catálogos de ventas de la empresa. Recuperada el 28-10-2014.

8. Este texto de José Marín Cañas sobre J. Sotillo Picornell es posible encontrarlo en La Nación, 13 de junio de 1969, pág. 95; así también en Valses nobles y sentimentales, publicado por EUNED y del mismo autor.

\section{Bibliografía}

Alvarado I., Hernández, E. y Vargas, S. (2004). La mirada del tiempo. Historia de la Fotografía en Costa Rica 1848-2003. San José, Costa Rica: Fundación Museos del Banco Central. Catálogo Exposición Nacional 1917 (1918). San José, Costa Rica: Imprenta Nacional.

Di Mare, L. Comunicación, Cultura y Sociedad. Caracas, Venezuela.

Marín Cañas, J. (1969). Sobre J. Sotillo Picornell. La Nación, 13 de junio de 1969. San José, Costa Rica.
- (2006). Valses nobles y sentimentales. San José, Costa Rica: EUNED.

Melgar Bao, A. (2009). El exilio venezolano en México. México: INAH.

Revista Athenea (1917), año 10, N. ${ }^{\circ}$ 3-4, San José, Costa Rica.

Revista El Cojo Ilustrado (1910), N. ${ }^{\circ}$ 0199. Caracas, Venezuela

Saavedra Hurtado, M. (1926). Guía Comercial de Costa Rica 1926-1927. San José, Costa Rica: Imprenta La Tribuna.

Sotillo Picornell, J.C. (1930 a.). Artículo en La nueva Prensa, Año IX, N. ${ }^{\circ}$ 2549, pp. 2-3. San José, Costa Rica.

- (1930 b.). Artículo en La nueva Prensa Año IX, N. ${ }^{\circ}$ 2550, pp. 6-11. San José, Costa Rica.

Urbina Gaitán, C. (2013). Las exposiciones Nacionales de Costa Rica 19171918. Revista de Ciencias Sociales, San José, Costa Rica: Editorial Universidad de Costa Rica. 